\title{
Robustly quantifying seafloor anoxia using uranium isotope data from ancient marine sediments
}

\author{
MICHAEL A. KIPP AND FRANÇOIS L.H. TISSOT
}

California Institute of Technology

Presenting Author: mkipp@caltech.edu

The seawater ${ }^{238} \mathrm{U} /{ }^{235} \mathrm{U}$ ratio (expressed $\delta^{238} \mathrm{U}$ ) has rapidly become one of the most widely-used proxies for reconstructing seafloor anoxia in deep time [1]. The proxy is built on the premise that one process $-U$ burial via reductive immobilization in anoxic sediments - dominantly controls the seawater $\delta^{238} \mathrm{U}$ value. Since the marine residence time of $U$ is far longer than ocean mixing timescales, the seawater $\delta^{238} U$ value is laterally and vertically homogenous, allowing samples from any location to constrain global $U$ isotope mass balance [2]. As such, any archive faithfully recording and preserving the seawater $\delta^{238} \mathrm{U}$ value on geologic timescales can be leveraged to reconstruct global marine anoxia in Earth's past. In practice, carbonate sediments have become the go-to archive for such investigations. Although preservation of $\delta^{238} \mathrm{U}$ signatures in carbonates on geologic timescales is a prerequisite for accurate reconstructions, and a non-trivial problem given the susceptibility of carbonates to post-burial alteration, for the sake of argument here we accept the assumption that such archives are accurate and ask the question: how can we most robustly quantify marine anoxia using a $\delta^{238} \mathrm{U}$ record?

While past work has used steady-state calculations or illustrative dynamic model outputs to constrain plausible extents of anoxia during snapshots of the past ocean or across transient perturbations, no study has systematically examined the potential inaccuracies of these quantitative reconstructions. Upon closer scrutiny, we find that "forward" modeling approaches are susceptible to spurious inferences of anoxia, particularly when seafloor anoxia is widespread, because the $\delta^{238} \mathrm{U}$ proxy loses its sensitivity at high levels of anoxia. To remedy this issue and promote robust quantification of seafloor anoxia within and among $\delta^{238} U$ datasets, we developed an "inverse" modeling framework for the treatment of sediment $\delta^{238} \mathrm{U}$ data [3]. We will discuss the application of this model to published datasets, highlighting the utility of this approach as well as problems and prospects for future work with the $\delta^{238} \mathrm{U}$ redox proxy.

[1] Zhang, F., et al. (2020), Geochimica et Cosmochimica Acta 287, 27-49.

[2] Tissot, F.L.H. \& Dauphas, N. (2015), Geochimica et Cosmochimica Acta 167, 113-143.

[3] Kipp, M.A. \& Tissot, F.L.H. (in review). 